\title{
An Inhibitory Innervation at the Gastroduodenal Junction
}

\author{
Sinn Anuras, Allan R. Cooke, and James Christensen \\ From the Gastroenterology Research Laboratories, Department of Internal \\ Medicine, University and Veterans Administration Hospitals, University of \\ Iowa College of Medicine, Iowa City, Iowa 52242
}

A в S т R A T Transverse muscle strips, 2-mm wide, were cut serially from the gastroduodenal junction in opossums, cats, dogs, and man. Electrical field stimulation with trains of rectangular current pulses of $0.5 \mathrm{~ms}$ in all opossums, all cats, some dogs, and the one human specimen induced relaxation in strips from the thickened circular muscle proximal to the mucosal junction. In some opossums weak relaxations also occurred in the first few strips below the mucosal junction. All other strips contracted or showed no response. This relaxation in opossums was abolished by tetrodotoxin but was not affected by antagonists to adrenergic and cholinergic transmission, nor by tripelennamine, methysergide, pentagastrin, secretin, cerulein, or cholecystokinin. Optimal frequency for stimulus-relaxation was $12 \mathrm{~Hz}$. Chronaxie was $0.85 \mathrm{~ms}$. The junctional strips also showed greater resistances to stretch than those remote from the junction. With apparent species variations, the junctional muscle possesses a nonadrenergic inhibitory innervation which is either absent or unexpressed in adjacent muscle of stomach and duodenum. This suggests the existence of a distinctive inhibitory neural control mechanism for pyloric muscle.

\section{INTRODUCTION}

In most species, the gastroduodenal junction (1-3) is marked by a thickening of the encircling muscle just above the mucosal border. This muscle has long been thought to have some special motor function. It is commonly called a sphincter with the unfound implication that it serves as a valve to regulate the egress of gastric contents. The term sphincter, ${ }^{1}$ though commonly applied to this and other junctions between alimentary organs, has never been precisely defined in physiological terms.

Reccived for publication 31 December 1973 and in revised form 19 March 1974.

"The term "pyloric sphincter," or "pylorus," is used throughout the text to indicate an anatomical location and not its function. The terms "gastroduodenal junction," or "relaxing strip," may be better and are used interchangeably with "pylorus" or "pyloric sphincter."
In a recent study, narrow strips of muscle cut from the esophagogastric junction were compared in terms of the motor responses to intramural nerves excited by electrical field stimulation to similar strips from regions adjacent to that junction. Those studies demonstrated the presence of an inhibitory innervation in the muscle of the esophagogastric junction which was absent in adjacent strips. This property seemed to characterize the segment commonly called the lower esophageal sphincter $(4,5)$. Those studies also indicated that the muscle of the esophagogastric junction shows a greater resistance to stretch than adjacent muscle.

The experiments described here were designed to discover similar distinguishing properties of the muscle of the gastroduodenal junction. The hypothesis was that both a distinctive inhibitory innervation and a high degree of resistance to stretch might also exist in the muscle of this junction to support the view that the gastroduodenal junction is physiologically distinct from the gastric antrum and duodenal bulb.

\section{METHODS}

Muscle was examined from the gastroduodenal junction in opossums, cats and dogs, and one man. The opossums, cats, and dogs were mature animals of both sexes, anesthetized by either intrapleural or intravenous (dogs) injection of sodium pentobarbital, $40 \mathrm{mg} / \mathrm{kg}$. The antrum and proximal duodenum were measured and marked in situ, removed en bloc, opened lengthwise either along the greater curvature or lesser curvature, and pinned flat to a beeswax block at the dimensions in situ, with the mucosa up. Those blocks of tissue, which were opened along the greater curvature so that the lesser curvature occupied the center of the longitudinal axis, were designed lesser curvature strips. The others were the greater curvature strips. The tissue was put in a tank of Krebs solution, aerated with $95 \% \mathrm{O}_{2}-5 \%$ $\mathrm{CO}_{2}$ at $36-38^{\circ} \mathrm{C}$. The Krebs solution had the following composition (mM): $\mathrm{NaCl}, 115.48 ; \mathrm{KCl}, 4.63 ; \mathrm{NaH}_{2} \mathrm{PO}_{4}$, 1.16; $\mathrm{NaHCO}_{3}, 21.91 ; \mathrm{CaCl}_{2}, 2.47 ; \mathrm{MgSO}_{4}, 1.16$; and glucose, 11.5. The junction between the gastric and duodenal mucosa was marked with a suture, and the mucosa was removed from a $5-\mathrm{cm}$ segment extending about $2.5 \mathrm{~cm}$ above and below the level of the mucosal junction. In opossums and cats a fibrous band, $1-\mathrm{mm}$ wide, was found encircling the gut in the muscular wall exactly at the level 


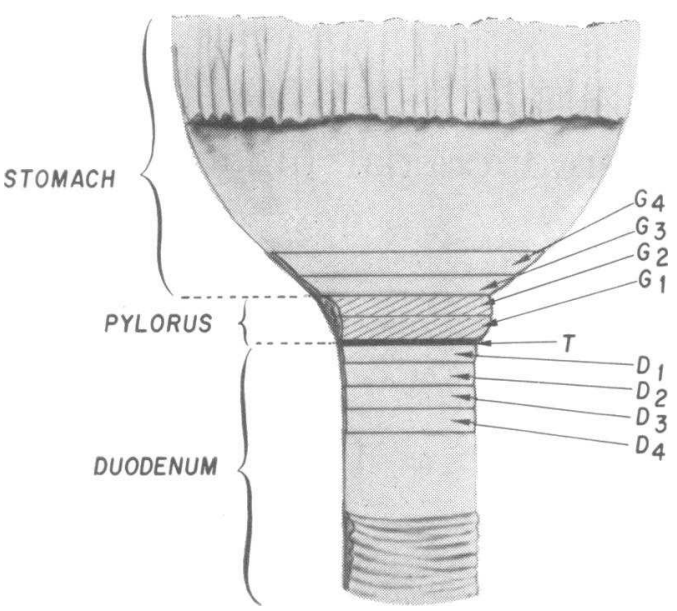

FIGURE 1 The scheme for cutting and labeling serial strips from the area of the gastroduodenal junction. The mucosa has been removed. $\mathrm{T}$ indicates the level of the mucosal junction where a fibrous band was encountered in some species. The hatched area, labeled pylorus, is the thick band of muscle seen in all species. The transverse lines and the letter-number designations indicate the serial strips described in the text.

of the mucosal junction, but no such band was seen grossly in the dogs or in man. Just proximal to this band, there was always a ring of thickened muscle, about $3-5-\mathrm{mm}$ wide. The muscular wall, exposed by mucosal removal, was then cut into 8-15 serial transverse strips, 2-mm wide and 1-1.5$\mathrm{cm}$ long by application of an assembly of razor blades mounted in a clamp. The single strip, which contained the fibrous band (in opossums and cats) and the corresponding level in dogs and man, was called the transition (or $\mathrm{T}$ ) ${ }^{2}$ strip. Those strips which lay on the gastric side were called $G$ strips and were numbered serially from the $T$ strip, $G_{1}, G_{2}, G_{3}$, and so on. Those strips which lay on the duodenal side were called $D$ strips and were similarly numbered from the $T$ strip, $D_{1}, D_{2}, D_{3}$, and so on (Fig. 1).

Each strip was mounted separately in a $75-\mathrm{ml}$ bath of $\mathrm{Krebs}$ solution aerated with $95 \% \mathrm{O}_{2}-5 \% \mathrm{CO}_{2}$ at $36.5-37.5^{\circ} \mathrm{C}$. In each bath, the strip was held in an electrode clip resembling that described by Blinks (6). One end of the strip was held in a plexiglass clip, while the other was fastened by a chain to a force-displacement transducer (Fig. 2). In position, each strip lay between two platinum wires, held $4 \mathrm{~mm}$ apart, which extended the length of the strip. The platinum wires were electrodes connected to the terminals of an electrical rectangular pulse generator. There were four such generators, so that four strips could be studied simultaneously. The stimuli were $0.5-\mathrm{ms}$ pulses delivered in 10-s trains at $10 \mathrm{cps}$ with $40-50 \mathrm{~V}$ of output from the pulse generators. Direct measurement of current with this equipment revealed that the current pulses were also nearly rectangular, with a current of $300 \mathrm{~mA}$ corresponding to a voltage output of $50 \mathrm{~V}$. Each strip was stretched to $150-180 \%$ of initial length before stimulation. Initial length was defined as the length of the strip at which a tension of $0.1 \mathrm{~g}$ was registered transiently when the rack-and-

${ }^{2}$ Abbreviations used in this paper: $\mathrm{D}_{1}, 2,3$, etc., serial strips of muscle from the duodenal side of the transitional strip; $G_{1,2}, 3$, etc., serial strips of muscle from the gastric side of the transitional strip; $\mathrm{T}$, transitional strip. pinion-mounted transducer was rapidly raised from a position at which the strip was slack. Tension and the stimulus signal were simultaneously recorded on a direct-writing recorder.

Initially, we observed relaxation of certain strips with field stimulation and mapped these relative to the anatomical features described above. Subsequently, strips showing this response were exposed to a variety of autonomic and other agents during stimulation. These agents are listed in Table IV. Secretin and cholecystokinin were obtained from the GIH Research Unit, Karolinska Institute, Stockholm. Cerulein was a gift from Farmitalia, Milan, and Pentagastrin was a gift from Ayerst Laboratories, New York. Each substance was added as a portion (not exceeding 2 $\mathrm{ml}$ ) of fresh stock solution in Krebs solution to achieve the indicated bath concentration. These were considered screening experiments, so that single large concentrations were used. The magnitude of resting tension and of stimulus-induced relaxation during control and after adding various agents was observed.

We sought to discover the optimal frequency for the relaxation. In each of 10 other opossums, the relaxing strip (usually the $G_{1}$ strip) was stimulated with 10-s trains of $0.5-\mathrm{ms}$ pulses of $300 \mathrm{~mA}$. Frequency was varied randomly from 1 to $20 \mathrm{~Hz}$. The relaxation amplitude for all stimuli at all frequencies were expressed as a percentage of the largest relaxation observed in each such strip, and the results were averaged for all 10 animals.

We examined the chronaxie (7) in those strips (usually $\mathrm{G}_{1}$ ) which were found to undergo stimulus-relaxation in a further 10 opossums. In these experiments, strips exhibiting the stimulus-relaxation were stimulated with single pulses of variable duration, being reduced from 10.0 to $1.0 \mathrm{~ms}$ in $1.0-\mathrm{ms}$ decrements and from $1.0 \mathrm{~ms}$ to $0.1 \mathrm{~ms}$ in $0.1-\mathrm{ms}$ decrements. At each pulse duration, current strength was increased from subthreshold levels until a relaxation was just apparent at the amplification, $5.0 \mathrm{~cm}$ of pen deflection/g of tension. For each of the 10 strips, plots were made of pulse length against current strength. Rheobase was taken as threshold current strength at $8-10 \mathrm{~ms}$ pulse length. Chronaxie was measured at the pulse duration at which threshold current strength was twice rheobase.

The relationship between length and tension was ex-

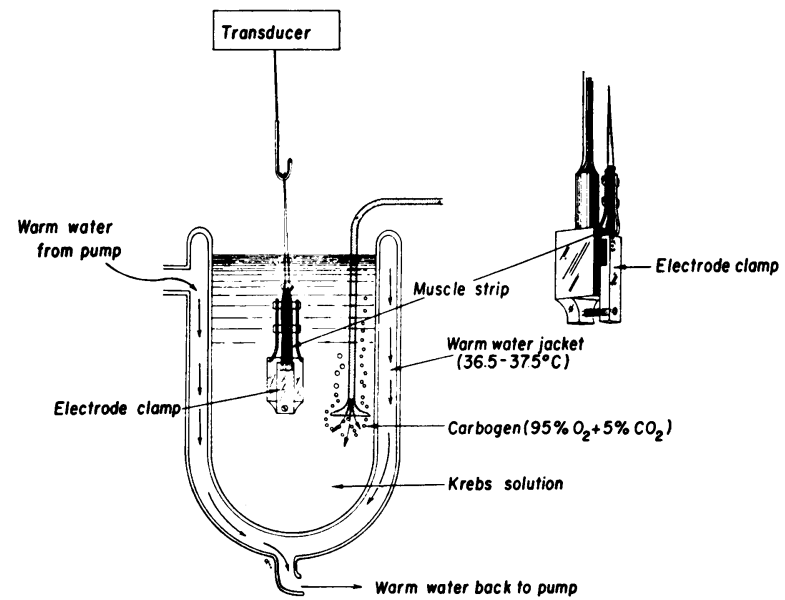

Figure 2 The mounting of the muscle strips. The jacketed bath is shown at the left. A perspective view of the spring clip holding the muscle between two platinum wire electrodes is at the right. 
amined in four opossums. Serial strips, cut in the way described above, were mounted in separate baths and attached to force-displacement transducers. Each rack-and-pinionmounted transducer was lowered until the muscle strip was slack and raised rapidly until $0.1 \mathrm{~g}$ of tension was registered transiently; tension quickly declined to zero. The length of the strip at this point was measured and designated as initial length. The tension of $0.1 \mathrm{~g}$ was chosen arbitrarily so as to ensure a consistent base-line length from which subsequent measurements could be made. The transducer was then raised to elongate the strip in steps; at least $5 \mathrm{~min}$ elapsed between each stretch. With each stretch, tension first increased and then declined, reaching a stable value within $1 \frac{1}{2} \mathrm{~min}$. Tension was measured at 2 min after each such stretch.

After completion of the length-tension experiments, each strip was transferred quickly to a different bath containing Krebs solution where electrical stimulation was done as described above. This procedure was used to identify the relaxing strip from the other strips studied by lengthtension. Some strips developed rhythmic contractions with stretch. In such strips tension was measured at the baseline between such rhythmic contractions. Plots were made of resting tension against length (as percent of initial length) for all strips in all animals. Plots were related in each animal by comparing their slopes and by comparing tension at $160 \%$ of initial length, stretches having been made through $200 \%$ of initial length.

\section{RESULTS}

Effects of electrical field stimulation. In 12 opossums, electrical field stimulation was always found to induce relaxation in 1 or 2 strips coming from the ridge of thickened muscle on the gastric side of the $\mathrm{T}$ strip. Neither relaxations nor contractions occurred in the other strips on the gastric side of the $T$ strip in response to stimulation. Typical responses from one opossum are given in Fig. 3. Some gastric strips exhibited spontaneous rhythmic contractions, and these were neither inhibited nor augmented by electrical field stimu-

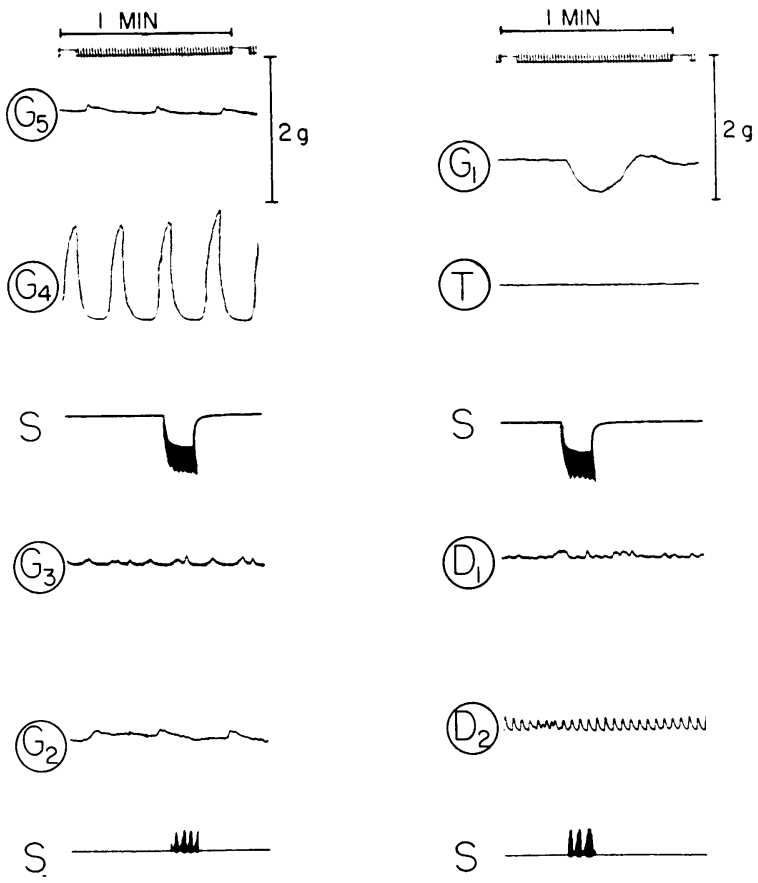

Figure 3 A record of the tension responses of eight serial strips from one opossum. The lines marked " $\mathrm{S}$ " indicate the signal for the stimulus, each line referring to the two tension records above it. The strips designated by $G$ are the first through fifth strips proximal to the strip from the level of the gastroduodenal mucosal transition, labeled $\mathrm{T}$. The strips labeled $\mathrm{D}$ are the first through second strip distal to the transitional strip. The tension and time calibrations apply to all strips. Observe that spontaneous contractions in some strips $\left(\mathrm{G}_{4}, \mathrm{D}_{2}\right)$ are unrelated to the stimulus.

lation. The breadth of the zone of stimulus-relaxation appeared to be slightly greater on the side correspond-

TABLE I

Kinds of Responses to Electrical Field Stimulation of Serial Transverse Muscle Strips at the Gastroduodenal Junction in Opossums*

\begin{tabular}{|c|c|c|c|c|c|c|c|c|c|c|c|c|}
\hline \multirow{3}{*}{$\begin{array}{c}\text { Strip } \\
\text { no. }\end{array}$} & \multicolumn{12}{|c|}{ Experiment no. } \\
\hline & \multicolumn{6}{|c|}{ Lesser curvature } & \multicolumn{6}{|c|}{ Greater curvature } \\
\hline & 1 & 2 & 3 & 4 & 5 & 6 & 1 & 2 & 3 & 4 & 5 & 6 \\
\hline $\mathrm{G}_{5}$ & & $\mathrm{~N}$ & & & & & & & & & & \\
\hline $\mathrm{G}_{4}$ & $\mathrm{~N}$ & $\mathrm{~N}$ & $\mathrm{~N}$ & $\mathrm{~N}$ & $\mathrm{~N}$ & & $\mathrm{~N}$ & $\mathrm{~N}$ & & $\mathrm{~N}$ & $N$ & $N$ \\
\hline $\mathrm{G}_{3}$ & $\mathrm{~N}$ & $\mathrm{~N}$ & $\mathrm{~N}$ & $\mathrm{~N}$ & $N$ & $\mathrm{~N}$ & $\mathrm{~N}$ & $N$ & $\mathrm{~N}$ & $\mathrm{~N}$ & $\mathrm{~N}$ & $\mathrm{~N}$ \\
\hline $\mathrm{G}_{2}$ & $\mathrm{~N}$ & $\mathrm{~N}$ & $\mathrm{~N}$ & $\mathrm{~N}$ & $\mathrm{~N}$ & $N$ & $\mathrm{R}$ & $\mathrm{R}$ & $\mathrm{N}$ & $\mathrm{N}$ & $\mathrm{N}$ & $N$ \\
\hline $\mathrm{G}_{1}$ & $\mathrm{R}$ & $\mathrm{R}$ & $\mathrm{R}$ & $\mathrm{R}$ & $\mathrm{R}$ & $\mathrm{R}$ & $\mathrm{R}$ & $\mathrm{R}$ & $\mathrm{R}$ & $\mathrm{R}$ & $\mathrm{R}$ & $\mathrm{R}$ \\
\hline $\mathrm{T}$ & $\mathrm{N}$ & $r$ & $r$ & $\mathrm{~N}$ & $\mathrm{~N}$ & $\mathrm{~N}$ & $\mathrm{~N}$ & $\mathrm{~N}$ & $\mathrm{R}$ & $\mathrm{R}$ & $\mathrm{R}$ & $\mathrm{R}$ \\
\hline $\mathrm{D}_{1}$ & $\mathrm{~N}$ & $N$ & $r$ & $\mathrm{~N}$ & $\mathrm{~N}$ & $N$ & $\mathrm{~N}$ & $\mathrm{~N}$ & $r$ & $\mathrm{~N}$ & $N$ & $r$ \\
\hline $\mathrm{D}_{2}$ & $\mathrm{~N}$ & $\mathrm{~N}$ & $\mathrm{r}$ & $N$ & $\mathrm{~N}$ & $N$ & $\mathrm{~N}$ & $N$ & $\mathrm{~N}$ & $\mathrm{~N}$ & $\mathrm{~N}$ & $\mathrm{~N}$ \\
\hline $\mathrm{D}_{3}$ & $N$ & & $\mathrm{~N}$ & $x$ & $\mathrm{~N}$ & $N$ & $N$ & $N$ & $\mathrm{~N}$ & $\mathrm{~N}$ & $\mathrm{~N}$ & $\mathrm{~N}$ \\
\hline $\mathrm{D}_{4}$ & & & & & & $\mathrm{~N}$ & & & $\mathrm{~N}$ & & & \\
\hline
\end{tabular}

* Abbreviations: $N$, no response; $R$, relaxation; $r$, slight relaxation (amplitude of relaxation less than $25 \%$ of $R$ ). 
TABLE II

Kinds of Responses to Electrical Field Stimulation of

Serial Transverse Muscle Strips from the Gastroduodenal Junction in Cats*

\begin{tabular}{|c|c|c|c|c|}
\hline \multirow{3}{*}{$\begin{array}{c}\text { Strip } \\
\text { no. }\end{array}$} & \multicolumn{4}{|c|}{ Experiment no. } \\
\hline & \multicolumn{2}{|c|}{ Lesser curvature } & \multicolumn{2}{|c|}{ Greater curvature } \\
\hline & 1 & 2 & 1 & 2 \\
\hline $\mathrm{G}_{5}$ & & $\mathrm{~N}$ & & \\
\hline $\mathrm{G}_{4}$ & $\mathrm{~N}$ & $\mathrm{~N}$ & $\mathrm{~N}$ & \\
\hline $\mathrm{G}_{3}$ & $\mathrm{~N}$ & $\mathrm{~N}$ & $\mathrm{~N}$ & $\mathrm{~N}$ \\
\hline $\mathrm{G}_{2}$ & $\mathrm{~N}$ & $\mathrm{R}$ & $\mathrm{N}$ & $\mathrm{N}$ \\
\hline $\mathrm{G}_{1}$ & $\mathrm{R}$ & $\mathrm{R}$ & $\mathrm{R}$ & $\mathrm{R}$ \\
\hline $\mathrm{T}$ & $\mathrm{R}$ & $\mathrm{N}$ & $\mathrm{R}$ & $\mathrm{R}$ \\
\hline $\mathrm{D}_{1}$ & $\mathrm{~N}$ & $\mathrm{~N}$ & $\mathrm{~N}$ & $\mathrm{~N}$ \\
\hline $\mathrm{D}_{2}$ & $\mathrm{~N}$ & $\mathrm{~N}$ & $\mathrm{~N}$ & $\mathrm{~N}$ \\
\hline $\mathrm{D}_{3}$ & $\mathrm{~N}$ & & $\mathrm{~N}$ & $\mathrm{~N}$ \\
\hline $\mathrm{D}_{4}$ & & & & $\mathrm{~N}$ \\
\hline
\end{tabular}

* See Table I for abbreviations.

ing to the greater curvature than on the side corresponding to the lesser curvature. Occasionally, a weak relaxation was seen in three to four strips on the duodenal side of the transitional strip. The distribution of stimulusrelaxation in all 12 opossums is shown in Table $\mathrm{I}$.

In four cats, the results were generally like those in the opossums. Prominent stimulus-relaxation occurred in two strips corresponding to the region of the thickened muscular segment just proximal to the transitional

TABLE III

Kinds of Responses to Electrical Field Stimulation of Serial Transverse Muscle Strips from the Gastroduodenal Junction in Dogs*

\begin{tabular}{|c|c|c|c|c|c|c|c|c|}
\hline \multirow{2}{*}{$\begin{array}{c}\text { Strip } \\
\text { no. }\end{array}$} & \multicolumn{8}{|c|}{ Experiment no. } \\
\hline & 1 & 2 & 3 & 4 & 5 & 6 & 7 & 8 \\
\hline $\mathrm{G}_{7}$ & & & & & & $\mathrm{C} \ddagger$ & $\mathrm{C}$ & $\mathrm{C}$ \\
\hline $\mathrm{G}_{6}$ & & & & & & $\mathrm{C}$ & $\mathrm{C}$ & $\mathrm{C}$ \\
\hline $\mathrm{G}_{5}$ & & & & & & $\mathrm{C}$ & $\mathrm{C}$ & $\mathrm{C}$ \\
\hline $\mathrm{G}_{4}$ & $\mathrm{C}$ & $\mathrm{C}$ & $\mathrm{C}$ & $\mathrm{C}$ & $\mathrm{C}$ & $\mathrm{C}$ & $\mathrm{C}$ & $\mathrm{C}$ \\
\hline $\mathrm{G}_{3}$ & C & C & C & C & C & $\mathrm{C}$ & $\mathrm{C}$ & $\mathrm{C}$ \\
\hline $\mathrm{G}_{2}$ & $\mathrm{C}$ & C & C & $\mathrm{C}$ & C & $\mathrm{C}$ & C & $\mathrm{C}$ \\
\hline $\mathrm{G}_{1}$ & $\mathrm{C}$ & C & $\mathrm{R}$ & $\mathrm{C}$ & $\mathrm{R}$ & C & $\mathrm{C}$ & $\mathrm{C}$ \\
\hline $\mathrm{T}$ & C & C & C & $\mathrm{C}$ & C & C & $\mathrm{C}$ & C \\
\hline $\mathrm{D}_{1}$ & $\mathrm{C}$ & $\mathrm{C}$ & C & $\mathrm{C}$ & C & C & $\mathrm{C}$ & C \\
\hline $\mathrm{D}_{2}$ & $\mathrm{C}$ & C & C & $\mathrm{C}$ & $\mathrm{C}$ & $\mathrm{C}$ & $\mathrm{C}$ & C \\
\hline $\mathrm{D}_{3}$ & $\mathrm{C}$ & $\mathrm{C}$ & C & C & $\mathrm{C}$ & $\mathrm{C}$ & $\mathrm{C}$ & $\mathrm{C}$ \\
\hline $\mathrm{D}_{4}$ & & & & & & $\mathrm{C}$ & C & C \\
\hline $\mathrm{D}_{5}$ & & & & & & $\mathrm{C}$ & $\mathrm{C}$ & $\mathrm{C}$ \\
\hline $\mathrm{D}_{6}$ & & & & & & $\mathrm{C}$ & C & $\mathrm{C}$ \\
\hline $\mathrm{D}_{7}$ & & & & & & $\mathrm{C}$ & $\mathrm{C}$ & C \\
\hline
\end{tabular}

* See Table I for abbreviations.

$\ddagger$, contraction.

S. Anuras, A. R. Cooke, and J. Christensen
TABLE IV

Effect of Various Drugs on the Relaxation Response

\begin{tabular}{lccl}
\hline \multicolumn{1}{c}{ Drwgs } & Concn & $\begin{array}{c}\text { No. } \\
\text { of } \\
\text { expts }\end{array}$ & \multicolumn{1}{c}{ Effects } \\
\hline Tetrodotoxin & $10^{-7} \mathrm{M}$ & 4 & Abolished relaxation \\
Atropine & $10^{-6} \mathrm{M}$ & 4 & No effect \\
Phenoxybenzamine & $10^{-4} \mathrm{M}$ & 4 & No effect \\
Phentolamine & $10^{-4} \mathrm{M}$ & 4 & No effect \\
Tolazoline & $10^{-4} \mathrm{M}$ & 4 & No effect \\
Propranolol & $10^{-5} \mathrm{M}$ & 4 & No effect \\
Hexamethonium & $10^{-4} \mathrm{M}$ & 4 & No effect \\
Nicotine & $10^{-4} \mathrm{M}$ & 4 & No effect \\
Tripelennamine & $10^{-4} \mathrm{M}$ & 4 & Increased resting tension \\
& $10^{-4} \mathrm{M}$ & 4 & No effect \\
Methysergide & $10^{-6} \mathrm{M}$ & 4 & No effect \\
Pentagastrin & $0.5 \mathrm{U} / \mathrm{ml}$ & 4 & No effect \\
Secretin & $5 \mathrm{U} / \mathrm{ml}$ & 4 & No effect \\
Secretin & $0.5 \mathrm{U} / \mathrm{ml}$ & 4 & Increased resting tension \\
Cholecystokinin & & & $(1 \mathrm{~g})$ \\
& $1.5 \times 10^{-8} \mathrm{M}$ & 4 & Increased resting tension \\
Cerulein & & & $(2-2.5 \mathrm{~g})$ \\
& & &
\end{tabular}

strip. Neither the more proximal gastric strips nor the duodenal strips responded to the stimulus at all (Table II).

In eight dogs, the responses were different from those of the opossums and cats. In two of the eight animals, one relaxing strip was found at the transitional region, not in the thickened muscle proximal to it. No relaxing strip was found in the other six dogs. All other strips in all animals contracted with the stimulation (Table III).

In the one human specimens obtained, two strips coming from the region of thickened muscle proximal to the transitional strip relaxed prominently. The first two duodenal strips relaxed slightly. All other strips contracted with stimulation.

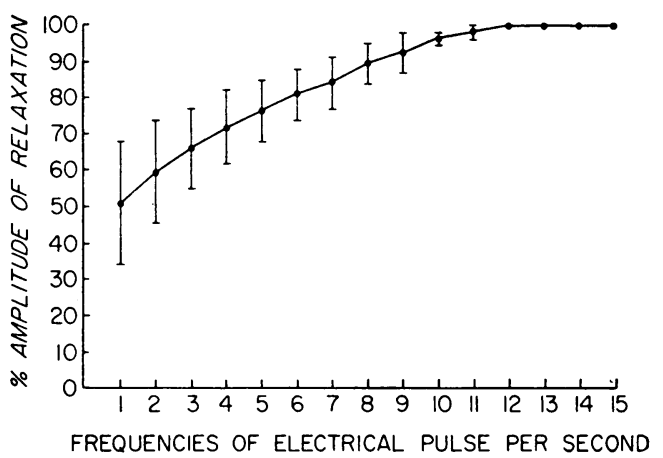

FIgURE 4 The graph of frequency against amplitude of relaxation. The amplitude of relaxation was measured while frequency was varied, with pulse length, $0.5 \mathrm{~ms}$, pulse strength, $300 \mathrm{~mA}$, and train length, $10 \mathrm{~s}$ all held constant. Responses were normalized in each animal as percent of the largest response seen. Points are averaged in 10 animals and bars indicate $1 \mathrm{SD}$ above and below the mean. Maximal responses were achieved at $12 \mathrm{~Hz}$, while single pulses elicited responses of about $50 \%$ the maximal amplitude. 
Effect of drugs on stimulus-relaxation. In 60 other opossums, we examined the effects of a variety of agents upon the stimulus-relaxation, seeking antagonism to that response (Table IV). Tetrodotoxin completely abolished stimulus-relaxation at $10^{-7} \mathrm{M}$, but the ability of the muscle to contract in response to long pulses (direct stimulation of the muscle) was still preserved, even at higher concentrations of tetrodotoxin. Tripelennamine, $10^{-4} \mathrm{M}$, cerulein $(8), 1.5 \times 10^{-8} \mathrm{M}$, and cholecystokinin, $0.5 \mathrm{U} / \mathrm{ml}$, all raised resting tension in the strips from the region of muscle thickening but did not alter the tension achieved during maximal stimulusrelaxation. All the other agents had no effect, either on resting tension or upon amplitude of stimulus-relaxation.

Chronaxie determination. In a further 10 opossums, the chronaxie for the stimulus-relaxation was found to be $0.85 \pm 0.3 \mathrm{~ms}$ (SD).

Effect of frequency variation. In 10 other opossums, the frequency of the stimulus was varied, keeping pulse length constant at $0.5 \mathrm{~ms}$ and strength constant at supramaximal current strength of $300 \mathrm{~mA}$. The optimal frequency was found to be about 12 cycles/s (Fig. 4). Single pulse experiments were done to see if the muscle behaved in the same manner as in response to train stimulation. Single pulses elicited relaxations (Fig. 5).

Length-tension determination. The comparisons of the length-tension relationships among the serial strips across the gastroduodenal junction showed a systematic variation much like that previously reported at the esophagogastric junction $(4,5)$. The steepest slopes always occurred in the transitional strips, while slopes of the relaxing strips (just proximal to the transitional strips) were usually greater than those of the strips remote from the transitional strips. Length-tension curves appeared to be linear through about $160 \%$ of initial length. The linear regression slopes through $160 \%$ of initial length for the length-tension curves for all strips in all four experiments are shown in Table $\mathrm{V}$. These slopes, for all strips in all animals, are plotted in Fig. 6 to show the spatial correlations of slope and relaxation

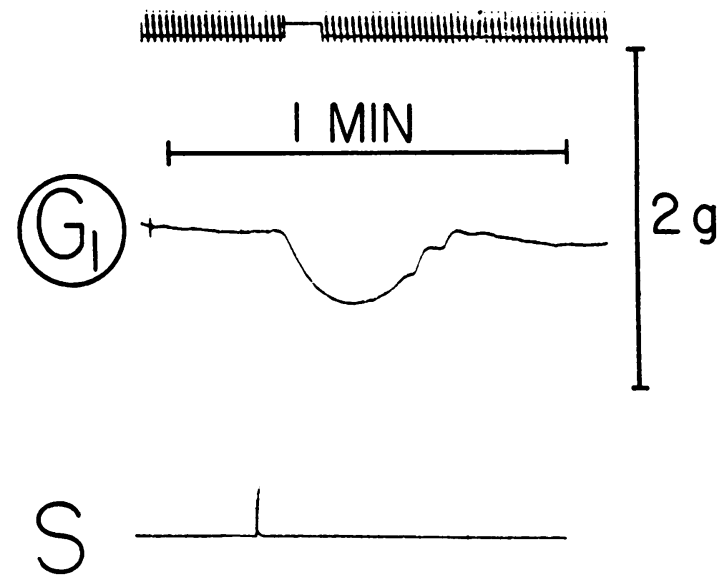

FIgURE 5 The relaxation response elicited by a single pulse. $G_{1}$ indicates that the strip was the first strip proximal to the transitional strip in this opossum. " $\mathrm{S}$ " indicates the stimulus signal. The marks at the top indicate seconds.

responses to electrical field stimulation. Some actual length-tension curves appear in Fig. 7.

\section{DISCUSSION}

These observations indicate the presence of stimulusrelaxation in the thickened ring of muscle at the gastroduodenal junction (which has long been considered to be the pyloric sphincter), a response which may be seen in an attenuated form for a short distance into the duodenum. There appears to be some degree of species variation, however, for it was found in all opossums and cats and in the one human specimen examined but in only two of eight dogs.

The ability of tetrodotoxin to abolish the response at $10^{-7} \mathrm{M}$ without abolishing contractions elicited by direct electrical excitation of the muscle (using a long pulse duration) indicates that the stimulus-relaxation is a response of the muscle to electrical excitation of intramural nerves. This conclusion is also supported by the fact that the response can be elicited by single pulses, by the chronaxie, and by the low value for optimal frequency.

\section{TABLE V}

Slopes of Length-Tension Curves for Serial Transverse Muscle Strips Cut from the Gastroduodenal Junction, as Determined by Least Squares Analysis*

\begin{tabular}{|c|c|c|c|c|c|c|c|c|c|}
\hline $\begin{array}{c}\text { Expt. } \\
\text { no. }\end{array}$ & $\mathrm{G}_{4}$ & $\mathrm{G}_{3}$ & $\mathrm{G}_{2}$ & $\mathrm{G}_{1}$ & $T$ & $\mathrm{D}_{1}$ & $\mathrm{D}_{2}$ & $\mathrm{D}_{3}$ & $\mathrm{D}_{4}$ \\
\hline 1 & 0.16 & 0.73 & $7.64(\mathrm{R}) \ddagger$ & $8.71(\mathrm{R})$ & 21.40 & $\mathrm{X} \S$ & 0.48 & 1.83 & - \\
\hline 2 & 3.29 & 0.61 & $8.47(\mathrm{R})$ & $8.91(\mathrm{R})$ & 21.02 & 4.97 & 0.96 & 0.69 & - \\
\hline 3 & - & 0.56 & 1.18 & $9.09(\mathrm{R})$ & $41.23(\mathrm{R})$ & $\mathrm{X}$ & 1.89 & 1.63 & 1.80 \\
\hline 4 & 0.72 & 0.66 & 3.00 & $8.35(\mathrm{R})$ & $36.37(\mathrm{R})$ & 6.80 & 2.58 & - & - \\
\hline
\end{tabular}

* Slope is calculated in terms of grams of tension per percentage of initial length.

$\ddagger R$, relaxing strip.

$\S \mathrm{X}$, tissue was broken during stretching. 


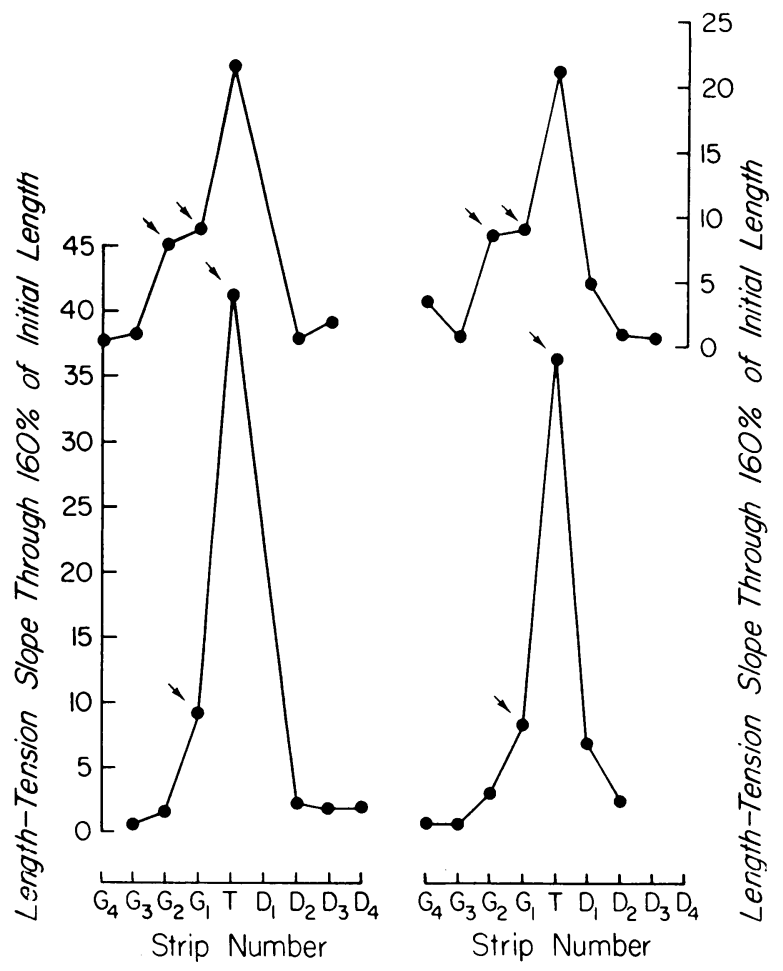

Figure 6 Slopes of length-tension curves (to $160 \%$ of initial length) for all transverse muscle strips cut serially across the gastroduodenal junction, correlated with a relaxation response to electrical field stimulation in four experiments. The linear slope of the length-tension curve through $160 \%$ of initial length is plotted on the vertical axis at the left for the two lower plots and on the right for the two upper plots. Strip numbers on the horizontal axis are defined in the text. Arrows indicate strips which showed a relaxation response to electrical field stimulation.

The reason is unclear for the relative steepness of the slopes of the length-tension curve of strips from the junction. It may represent only the differences in composition of the strips. The transitional strip seemed to have more connective tissue than the others, and the duodenal strips contained Brunner's glands. However, the differences in slopes might be myogenic, as they appear to be in the esophagus (9).

The idea of a distinctive innervation of the muscle of the gastroduodenal junction is an old one. Gaskell in 1916 (10) proposed that the muscle of the cardiac and pyloric sphincters are derived from different primal tissues from muscles of the esophagus, stomach, and small bowel and that the innervation should also, therefore, be different. He supported his argument by citing prior evidence that pyloric muscle responded differently to epinephrine than adjacent muscle. Thomas and Wheelon in 1922 (11) opposed Gaskell's view as a consequence of their experiments with electrical excitation of the extrinsic nerves of the gut. Electrical stimulation of the vagi and splanchnic nerves (in dogs) usually elicited contractions of antrum, pylorus, and duodenum, although sometimes relaxations occurred at the pylorus, a response which Thomas and Wheelon attributed to epinephrine release, claiming that the dog pylorus differed from that of other species in being inhibited by epinephrine. The view at that time was that the pylorus had no independent role in gastric emptying, with the implication that it has no special neural control system independent or different from that of adjacent regions (12). The majority of work done to the present time on this matter has been done in the dog.

The results of these experiments suggest that dogs differ from cats and opossums (and possibly man) in respect to the innervation of the pylorus. At least in the latter three species, there does, indeed, appear to be distinctive inhibitory innervation to the pylorus. The lack of effect of the antagonists suggests that this response is mediated by nonadrenergic inhibitory nerves. Similar nonadrenergic inhibitory nerves have been demonstrated by similar techniques to be present at the esophagogastric junction in the region commonly considered to be the lower esophageal or cardiac sphincter $(4,5)$. The nerves of these two regions differ in one respect. The chronaxie of these nerves at the opossum pylorus, $0.85 \mathrm{~ms}$, is considerably longer than that of the nerves to the esophagogastric junction of the opossum, $0.50 \mathrm{~ms}$ (unpublished data), but this may indicate only a difference in nerve diameter.

Nonadrenergic inhibitory nerves have been clearly demonstrated in the colon in a variety of species. Burn-

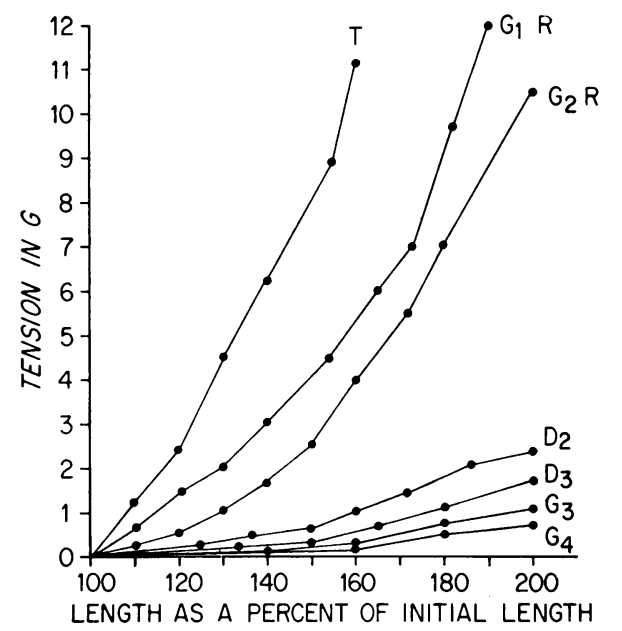

Figure 7 Length-tension curves in serial strips cut from the region of the gastroduodenal junctions in one opossum. Tension, in grams, appears on the vertical axis. Length, as percentage of initial length (as defined in the text), appears on the horizontal axis. Each curve represents one strip. Curves are labeled as to positions, as defined in the text ( $D_{1}$ strip was broken in early stretching). " $R$ " indicates the two strips in this animal which relaxed with electrical field stimulation. 
stock (13) has recently reviewed the nonadrenergic inhibitory (purinergic) nervous system and indicated that in the stomach the cell bodies of these neurons are probably localized in Auerbach's plexus. However, further regional localization has not been possible with present techniques. The only physiological mechanism that has been found to operate in the stomach as a result of stimulation of nonadrenergic inhibitory nerves is receptive relaxation of the fundus (14). The present experiments suggest that the gastroduodenal junction, as well as the esophagogastric junction, may have a nonadrenergic inhibitory innervation independent of adjacent tissues, and this may constitute part of the definition of the sphincteric function.

Fisher, Lipshutz, and Cohen (15) studied the tension of the pyloric sphincter in the opossum in vitro and in man by manometry. They observed in the opossum an increase in resting tension with secretin and cholecystokinin but not with gastrin, a finding we have partially confirmed. We did not observe an effect with secretin and pentagastrin, but cholecystokinin and cerulein both raised resting tension. Fisher and co-workers (15) generally confirmed their in vitro findings in their in vivo studies in man. It is difficult to determine whether manometric techniques used in those experiments (15) could localize changes in the tension of the pylorus, since the length of the gastroduodenal junction from our studies appears to be $2-4 \mathrm{~mm}$.

The role of the antrum and the pylorus in controlling gastric emptying is difficult to assess at present. In general, secretin, cholecystokinin, and gastrin delay emptying in man $(16,17)$ and $\operatorname{dog}(18)$ but have different effects on antral motor activity $(18,19)$. Furthermore, a distinction must be made between the gastric emptying of liquids and solids, since removal of the pylorus in dogs has little effect on the gastric emptying of liquids but markedly accelerates that of solids (20). Extrapolation of our in vitro findings in the dog to the in vivo situation is difficult in the present stage of our knowledge.

These experiments do not establish the pylorus as a sphincter, nor do they carry any implication about a role for the pylorus in the regulation of gastric emptying. They do, however, indicate that the muscle of the gastroduodenal junction is distinct from adjacent muscle in the nature of its innervation. The presence of distinctive nonadrenergic nerves suggests that the pylorus must, at times, be made to relax by nerve action. Whether or not this is of real physiological importance in the process of gastric emptying remains to be seen.

\section{ACKNOWLEDGMENTS}

This work was supported in part by research grants AM 11242 and AM 15886, and in part, by training grant A.M 5390 , all from the National Institutes of Health.

\section{REFERENCES}

1. Didio, L. J. A., and M. C. Anderson. 1968. The "Sphincters" of the Digestive System. The Williams and Wilkins Co., Baltimore. 95-118.

2. Torgersen, J. 1942. The muscular build and movements of the stomach and duodenal bulb. Acta Radiol. Suppl. $45: 1-191$.

3. Edwards, D. A. W., and E. N. Rowlands. 1968. Physiology of the gastroduodenal junction. Handb. Physiol. 4: $1985-2000$.

4. Christensen, J., B. W. Freeman, and J. K. Miller. 1973. Some physiological characteristics of the esophagogastric junction in the opossum. Gastroenterology. 64: 1119-1125.

5. Christensen, J., J. L. Conklin, and B. W. Freeman. 1973. Physiologic specialization at the esophagogastric junction in three species. Am. J. Physiol. 225: 12651270 .

6. Blinks, J. R. 1966. Field stimulation as a means of effecting the graded release of autonomic transmitters in isolated heart muscle. J. Pharmacol. Exp. Ther. 151: 221-235.

7. Fredericg, H. 1928. Chronaxie. Testing excitability by means of a time factor. Physiol. Rcv. 8: 501-535.

8. Erspamer, V. 1970. Progress report: cerulein. Gut. 11: $79-8 \%$.

9. Christensen, J., and J. L. Conklin. 1974. Studies on the origin of the distinctive machanics of smooth muscle at the esophagogastric junction. Proceedings of the 4th International Symposium on Gastrointestinal Motility. Mitchell Press, Vancouver. In press.

10. Gaskell, W. H. 1920. The Involuntary Nervous System. Longmans Green and Co., Ltd., London. 2nd edition. 43-49.

11. Thomas, J. E., and H. Wheelon. 1922. The nervous control of the pyloric sphincter. J. Lab. Clin. Med. 7: 375-391.

12. Thomas, J. E. 1957. Mechanics and regulation of gastric emptying. Physiol. Rev. 37: 453-474.

13. Burnstock, G. 1972. Purinergic nerves. Pharmacol. Rei'. 24: 509-581.

14. Abrahamsson, H. 1973. Studies in the inhibitory nervous control of gastric motility. Acta Physiol. Scand. Suppl. 390: $5-38$.

15. Fisher, R. S., W. Lipshutz, and S. Cohen. 1973. The hormonal regulaticn of pyloric sphincter function. $J$. Clin. Invest. 52: 1289-1296.

16. Hunt, J. N., and N. Ramsbottom. 1967. Effect of gastrin II on gastric emptying and secretion during a test meal. Br. Med. J. $4:$ 386-387.

17. Chey, W. Y., S. Hitanant, J. Hendricks, and S. H. Lorber. 1970. Effect of secretin and cholecystokinin on gastric emptying and gastric secretion in man. Gastrocutcrology. 58: 820-827.

18. Cooke, A. R., T. E. Chvasta, and N. W. Weisbrodt. 1972. Effect of pentagastrin on emptying and electrical and motor activity of the dog stomach. Am. J. Physiol. 223 : 934-938.

19. Chvasta, T. F., and A. R. Cooke. 1973. Secretin-gastric emptying and motor activity: natural versus synthetic secretin. Proc. Soc. Exp. Biol. Med. 142: 137-142.

20. Dozois, R. R., K. A. Kelly, and C. F. Code. 1971. Effect of distal antrectomy on gastric emptying of liquids and solids. Gastrocnterology. 61: 675-681. 